\title{
An Optimal Production/Maintenance Strategy under Lease Contract with Warranty Periods
}

\author{
Zied Hajej ${ }^{1}$, Nidhal Rezg ${ }^{2}$, and Ali Gharbi ${ }^{3}$ \\ ${ }^{1}$ Hajej. Zied., LGIPM-Lorraine University, Metz, 57045 France. \\ ${ }^{2}$ Rezg. Nidhal LGIPM-Lorraine University, Metz, 57045 France \\ ${ }^{3}$ Gharbi. Ali, Département de la production automatisée, Ecole de Technologie Supérieure, \\ Montréal, Canada.
}

\begin{abstract}
This paper investigates the optimal production policy and maintenance strategy for leased equipment under a lease contract with warranty periods. In order to have steady revenue, the lessor (owner) of the equipment may provide guaranty periods to encourage the lessee to sign a lease contract with a longer lease period. Under this production/maintenance scheme, the mathematical model of the expected total cost is developed and the optimal production planning and the corresponding optimal maintenance policy are derived by choosing the optimal warranty periods for the lessee in order to minimize the total cost. The influence of the production rates variation in the equipment degradation is considered by an increasing failure rate according to both time and production rates. The impact of warranty periods on optimal maintenance planning will be studied thereafter. Finally, numerical examples are given to illustrate the analytical study and the effects of the warranty periods variation during the lease periods on the maintenance policy and consequently on the total cost.
\end{abstract}

Keywords - forecasting, lease contract, failure rate, random demand, service level, minimal repair

\section{INTRODUCTION}

Ameliorating the situation of an industry requires certainly reducing costs and maximizing the customer satisfaction. These two goals cannot be achieved without a good management and a good knowledge while making decisions. Aware of the superfluous costs that possessing resources which can be sometimes pointless, subcontracting and leasing have become very important for many manufacturing fields because of the advantage that these solutions can bring. Concerning the leasing context, the lease payment and maintenance service of production equipment are very important items in the lease contract for the manufacturer. That is due to the expensive production equipment and consumers' variable necessities on the functionality of a product for which it is not economical for the manufacturer to purchase the expensive production equipment.

In the literature, we can find different attempts to study the leasing problem. In order to reduce the cost of production, which requires the expensive production equipment, which is not economical for the company, many manufacturers usually lease their production equipment rather than purchasing them [8].

Concerning the maintenance service in the leasing contract, many works treated the type of this problem. For maintenance aspect, two types of maintenance actions are considered: corrective maintenance (CM) and preventive maintenance (PM). PM improves

$\overline{\text { Communicating author's email: zied.hajej@univ-lorraine.fr }}$ 
the operational state of the leased equipment, thereby decreasing the likelihood of equipment failure, whereas CM repairs failed equipment back to its operational state. There is an enormous literature dealing with maintenance policies ([1];[2]; [3]). In general, the lease depends on the length of the leased period and the specified maintenance service required by the lessees. A longer length of the leased period is expected to increase the revenue of lessors, and the maintenance cost of the equipment rises as well. In this context, [8] treated the maintenance of the facility that will be generally specified in a lease contract to ensure that the facility could fulfill its intended performance. For reducing the maintenance and penalty costs, several lessors take on preventive maintenance actions to decrease the number of the equipment failures within the leased period. Remaining with the maintenance aspect, but with the guarantee, [14] proposed a mathematical model for the optimal one-dimensional unlimited free-replacement warranty policy with replacements carried out with reconditioned products. The objective of this study is to compute the optimal warranty and production parameters which maximize the total profit.

On the other hand, various researches were performed to treat the problem of joint production and maintenance optimization. In this context, we can mention the work performed by [9] and which proposes a joint stochastic optimization of the production considering a corrective and preventive maintenance. The authors proposed a method to optimally determine the periodicity of the preventive maintenance and the maintenance ratio for the case of identical machines in the production chain. The model in [10] is based on the simultaneous optimization of the flow of the production and the preventive maintenance. Another category deals with production/maintenance optimization based on deteriorating production systems with buffer stocks, which reduces the impact of troubleshooting on the productivity and satisfying the demand during the preventive maintenance period. This category is developed principally by [11] and [12]. [13] proposed an inspection strategy for a multi-state system where it can be in nominal operating state, degraded state or failure state. A maintenance action is undertaken when at a predetermined instant an inspection reveals that the system is in degraded or failure state. The objective of this study is maximize the productivity of the multi-state system by using a periodic type inspection strategy.

A number of different integrated maintenance policies have been proposed in the literature. Small lists of works treat the maintenance problem with the consideration of the equipment failure according to the production rate. Recently [6], [7] considered that the status of machines depend on their production rate and time during which they have worked and consider the influence of production on the degradation of machine and consequently in maintenance planning of production system which has to satisfy a random demand during a finite horizon given a required service level.

Motived by our recently work in [15], we proposed a mathematical model to study the opportunity provided by the extended warranty for the lessee as well as for the lessor under leasing contract. We express the total cost incurred by each side during the product's life cycle in order to determine the maximum extra cost the lessee should pay for the extended warranty, and the minimum price at which the manufacturer should sell it. We will be looking, for any given situation, if there is a zone of possible compromise yielding a winwin relationship with respect to the extended warranty. This study shows that it has a novelty and originality relative to this type of problem which considers the impact of leasing/warranty contract on the production/maintenance problem. Indeed, it has been 
shown the production and maintenance plan optimization during the leasing period characterising by the economical production plan, optimal maintenance strategy and optimal warranty periods.

Our objective is to optimize the production plan during the leasing period to satisfy the random demand and optimize the maintenance strategy, characterized by the optimal number of preventive maintenance actions, by selecting the optimal warranty length for the lessee that minimizes the sum of the inventory and the production costs along with the costs associated with the maintenance policy. A sensibility study is proposed in order to determine the impact of failure rate at the end of guarantee period on the maintenance strategy since the lessor leaves the equipment with unknown failure rate at the end of guarantee period.

This remainder of this paper is organized as follows: Section 2 presents a description of the optimization problem. Section 3 proposes a general stochastic production, inventory and maintenance model. Section 4 presents and develops the policy and analytical expression of production/inventory and of maintenance. A simple numerical example is presented in section 5. Finally, the conclusion is given in Section 6.

\section{PROBLEM DESCRIPTION}

\subsection{NOTATION}

We used the following notations in this paper:

\begin{tabular}{|c|c|}
\hline$\Delta t$ & length of a production period \\
\hline$H$ & number of production cycle \\
\hline$k$ & index of production periods in cycle $i k\left(k=0,1, \ldots, h_{i}\right)$ \\
\hline$h_{i}$ & $\begin{array}{l}\text { number of production period } k\left(k=0,1, \ldots, h_{i}-1\right) \text { in cycle } i \\
(\mathrm{i}=0,1, \ldots, H)\end{array}$ \\
\hline$L$ & number of periods $\Delta \mathrm{t}$ in one leasing cycle \\
\hline$L . \Delta t$ & lease period $=\sum_{i=0}^{H} h_{i} \cdot \Delta t$ \\
\hline $\mathrm{X} . \Delta t$ & warranty period \\
\hline$u_{k}:$ & $\begin{array}{l}\text { production quantity of machine } M \text { during period } k(k=0,1, \ldots \text {, } \\
\left.h_{i}-1\right)(\mathrm{i}=0,1, \ldots, H)\end{array}$ \\
\hline$\hat{d}(k)$ & average demand during period $k\left(k=0,1, \ldots, h_{i}\right)(\mathrm{i}=0,1, \ldots, H)$ \\
\hline$V_{d(k)}$ & variance of demand during period $k\left(k=0,1, \ldots, h_{i}\right)(\mathrm{i}=0,1, \ldots, H)$ \\
\hline$S_{k}$ & $\begin{array}{l}\text { inventory level at the end of period } k\left(k=0,1, \ldots, h_{i}\right) \\
(\mathrm{i}=0,1, \ldots, H)\end{array}$ \\
\hline$\hat{S}_{k}$ & $\begin{array}{l}\text { average inventory level of } S \text { during period } k\left(k=0,1, \ldots, h_{i}\right) \\
(\mathrm{i}=0,1, \ldots, H)\end{array}$ \\
\hline$C_{p r}$ & unit production cost of machine $M$ \\
\hline Cs & unit product holding cost per period \\
\hline
\end{tabular}




\begin{tabular}{|l|l|}
\hline$m u$ & monetary unit \\
\hline $\mathrm{U}^{\text {max }}$ & maximum production quantity of machine $M$ \\
\hline $\mathrm{U}^{\text {min }}$ & minimum production quantity of machine $M$ \\
\hline$\alpha$ & $\begin{array}{l}\text { probability index related to customer satisfaction and } \\
\text { expressing the service level. }\end{array}$ \\
\hline$S_{0}$ & initial inventory. \\
\hline$\lambda_{X}$ & Failure rate at the end of warranty periods. \\
\hline
\end{tabular}

\subsection{PROBLEMATIC}

In this work, we deal with the problem of joint optimization of production and maintenance planning under a relatively new angle considering a leasing constraint with warranty periods. The idea of our problem consists in determining the best production planning multi-periods and maintenance strategies. Firstly, before submitting the problem, we note that the lease contract comprises three components: (i) lessor (who owns and maintains the equipment), (ii) lessee (who leases the equipment), and (iii) lease contract (which deals with the price and conditions of lease). The lessor offers the product (equipment) and the service (maintenance) as a bundle to the lessee.

The proposed model for this problem is a finite multi-periods, discrete-time model. We suppose, also, that all the manufacturing system is designed in order to produce only one type of product and composed of a single machine $M$ and one store $S$ is the manufacturing store (where the manufactured products are stored and where the customer receives his demand (products)). The customer demand which is denoted by $d$ is random and distributed according to a Normal distribution with mean and standard deviation given respectively by $\hat{d}$ and $\sigma_{d}$.

The equipment is leased for a period $L \cdot \Delta t$ with a warranty periods $X \cdot \Delta t$. The contract $L / X$ involves that the machine is under warranty during the $X \cdot \Delta t$ periods, namely that all maintenance actions during the warranty periods $X \cdot \Delta t$ are supported by the lessor. For the rest of period's i.e. $(L-X) \cdot \Delta t$, the equipment is not under warranty and the maintenance actions are under the responsibility of the lessee.

The leasing period $L \cdot \Delta t$ covers all the production cycle thus $L \cdot \Delta t=\sum_{i}^{H} h_{i} \cdot \Delta t$. Machine $M$ is subject to a random failure. The probability degradation law of machine $M$ is described by the probability density function of time to failure $f(t)$ and for which the failure rate $\lambda(t)$ increases with time and according to the production rate $u_{k}$.

Our objective is to optimize the production rates of the different horizons $h_{i} \cdot \Delta t$ satisfying the random demand and the maintenance actions strategy by choosing the best value of warranty periods $X \cdot \Delta t$ for the lessee. The choice of $X$ influences the costs of preventive and corrective maintenance actions per period because the maintenance actions costs have become more expensive if the warranty periods increase. If we assume two different warranty periods $X_{1}$ and $X_{2}$ with $X_{1} \leq X_{2}$, the corrective and preventive maintenance costs 
of $X_{1}$ are cheaper compared to the preventive and corrective maintenance costs of warranty period $X_{2}$. Thus we assume that $M_{c}\left(X_{j+1}\right)=\delta \cdot M_{c}\left(X_{j}\right)$ and $M_{p}\left(X_{j+1}\right)=\delta \cdot M_{p}\left(X_{j}\right)$ with $X_{j+1}>X_{j} ; X=X_{j} ; j=\{1,2, \ldots\}$ warranty periods and $\delta$ is the progress coefficient of preventive and corrective maintenance costs. Also we assume that the reliability of the machine at the end of warranty periods $X \cdot \Delta t$ is $R(X)<1$ and the lessor leaves the equipment with unknown failure rate. The aim is to minimize the sum of the inventory and the production costs along with the costs associated with the maintenance policy.

The following design illustrates the general problem that our work deals with:

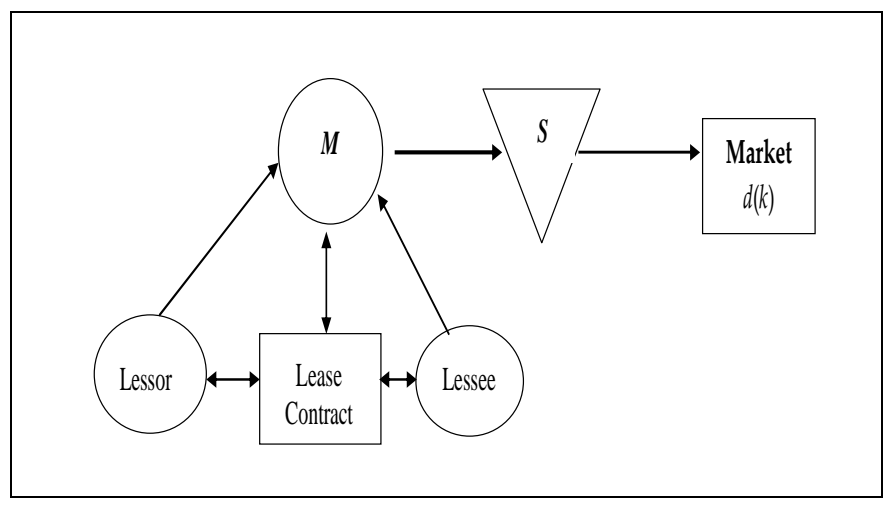

Figure 1: Problem Description

\section{MATHEMATICAL FORMULATION}

\subsection{TOTAL PRODUCTION/MAINTENANCE COST}

The idea is to determine the best combination of production rates and inventory levels that minimize the average total costs over the finite time multi-horizon $L . \Delta t$ and that with bearing in mind the necessity of satisfying the fluctuating demand. Each horizon is divided equally into $h i$ periods. Also, as we mentioned above, our model takes into account some constraints on main variables and that in order to make the resolution more realistic and closer to concrete cases. The stochastic problem as follows:

$f_{k}($.$) denotes functions that represent the expected value of production and inventory costs.$ The maintenance cost $C_{M}($.$) is characterized by the preventive and corrective maintenance$ costs and the expected number of failures. 


$$
\underset{(U, N)}{\operatorname{Min}}\left(\begin{array}{l}
\left\{\sum_{i=0}^{H} f_{h_{i}}\left(S_{h_{i}}\right)+\sum_{i=0}^{H} \sum_{k=0}^{h_{i}-1} f_{k}\left(S_{i, k}, u_{i, k}\right)\right\} \\
+\left\{C_{M}(U, N)\right\}
\end{array}\right)
$$

With $f_{h_{i}}$ the expected inventory costs at period $h_{\mathrm{i}}$ where we don't consider the production order at the end of the horizon $h_{i}$.

Our main constraints can be given by:

For each horizon $h_{i} \Delta t$, the inventory level at the period $k+l$ equals to the inventory level at the period $k$ plus the production quantity during period $k$, minus the demand during period $k$. In our work, we assume that net inventory levels should be calculated at the end of each production period.

Otherwise, the net inventory level should obey to the following equation:

$$
S_{i, k+1}=S_{i, k}+u_{i, k}-d_{i, k} \quad k \in\left\{0,1, \ldots, h_{i}-1\right\} ; i \in\{0,1, \ldots ., H\}
$$

The service level requirement constraint for each period for each horizon is expressed by the following constraint.

$$
\operatorname{Prob}\left[S_{i, k+1} \geq 0\right] \geq \alpha \quad k \in\left\{0,1, \ldots, h_{i}-1\right\} ; i \in\{0,1, \ldots ., H\}
$$

The uncertainty about fluctuation of the demand brings randomness to the first constraint (2). Therefore, the inventory and production variables are stochastic and their statistics depend on the probabilistic distribution functions of demand. Thus may explain the use of probabilistic constraint. Such constraint can, also, be useful to help manager to analyze diverse situations and scenarios of producing. For example, varying the value of $\alpha$ in (3), the manager can analyze various storage policies and therefore look forward to improving customer satisfaction.

The following constraint defines an upper and lower bounds on the production level during each period $k$.

$$
0 \leq u_{i, k} \leq U^{\max } \quad k \in\left\{0,1, \ldots ., h_{i}-1\right\} ; i \in\{0,1, \ldots ., H\}
$$

\subsection{Production POLICY}

In this subsection, a constrained stochastic optimal problem is formulated. It is used to represent a constrained production problem under lease contract with warranty periods, service level and random demand. 
The mathematical model provides a decision rule that optimize the inventory, production policy. The principle characteristic of production policy is the use of a quadratic cost function allowing penalizing both excess and shortage in the inventory level. The used quadratic model is based on a well known approach (HMMS). In our problem, we adapted this HMMS model to establish an inventory and production policy[5].

The expected cost including production and holding costs for the period $k$ is given by:

$$
f_{k}\left(S_{i, k}, u_{i, k}\right)=C_{s} \cdot E\left\{S_{i, k}^{2}\right\}+C_{p r} \cdot u_{i, k}^{2}
$$

Note that $E\{\}$ denotes the mathematical expectation operator.

The quadratic total expected cost of production and inventory over the leasing period can then be expressed as follows:

$$
F(u)=\sum_{i=0}^{H} \sum_{k=0}^{h_{i}} f_{k}\left(u_{i, k}, S_{i, k}\right)=\sum_{i=0}^{H} C_{s} \cdot E\left\{S_{h_{i}}^{2}\right\}+\sum_{i=0}^{H} \sum_{k=0}^{h_{i}-1}\left[C_{s} \cdot E\left\{S_{i, k}^{2}\right\}+C_{p r} \cdot u_{i, k}^{2}\right]
$$

\subsection{Maintenance Policy:}

In this subsection, we describe the maintenance strategy for the equipment from the lessee side after the warranty periods of the leasing periods. Recall that the lease contract includes the maintenance of the leased equipment during the $X$ periods of warranty i.e. the preventive and corrective maintenance actions during the warranty periods $X$ are covered by the lessor. Once the warranty period is over the maintenance actions are under the charge of the lessee and the maintenance actions costs have become more expensive during the subsequent periods.

The maintenance strategy adopted which is preventive maintenance with minimal repair. For a given finite horizon $(L-X)$. $\Delta t$ (leasing periods) divided equally into $N$ parts of duration $T$, the adopted maintenance policy is defined as follows. An overhaul of the equipment is performed at times $q \cdot T(q=1,2, \ldots . N)$. An overhaul consists in replacing some critical parts restoring the equipment to an as good as new condition. When the equipment fails between successive overhauls, minimal repair is done. It is assumed that the repair and overhaul durations are negligible.

Formally, the influence of the production rates variation in the equipment degradation is considered by an increased failure rate according to both time and production rates [7]. The goal is to determine the optimal maintenance strategy, characterized by the optimal number $N^{*}$ of preventive maintenance actions to perform over the finite horizon $(L-X) . \Delta t$. 


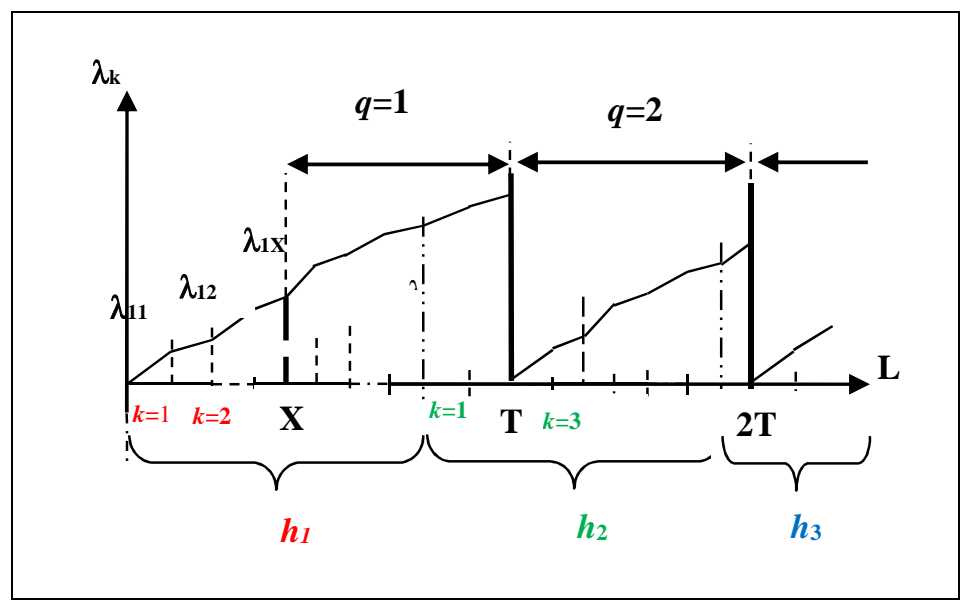

Figure 2: Failure Rate

The average maintenance cost is expressed as follows:

$$
C_{M}(U, N)=(N-1) \cdot M_{p}+M_{c} \cdot A(U, N) \text { with } T=\frac{(L-X)}{N} \cdot \Delta t
$$

Where $A(U, N)$ is the average number of failures as a function of the production plan defined by the vector $U$ and the number of preventive maintenance actions $N$.

\section{AnAlytical STUDY}

In this section, we would like to show the jointly optimization of production and maintenance plans by the analytical study of policies and establish the deterministic equivalent problem.

\subsection{PRODUCTION AND INVENTORY COSTS}

An approach that transforms the stochastic problem into a deterministic equivalent is necessary. This deterministic problem maintains the main properties of the original problem.

Before proceeding, the following notation is introduced:

Mean variables:

$E\left\{S_{i, k}\right\}=\hat{S}_{i, k}, E\left\{u_{i, k}\right\}=u_{i, k}$

Variance variables: $V_{U_{i, k}}=0$. (Note that this reflects the fact that the control variables $u_{i, k}$ is deterministic).

- $\quad$ The production and inventory costs simplify as:

\section{Lemma1:}




$$
F(u)=\sum_{i=0}^{H} C_{s} \times\left(\hat{S}_{i, h_{i}}{ }^{2}\right)+\sum_{i=0}^{H} \sum_{k=0}^{h_{i}-1}\left[C_{s} \cdot \hat{S}_{i, k}{ }^{2}+C_{p r} \times u_{i, k}{ }^{2}\right]+C_{s} \times\left(\sigma_{d_{i}}\right)^{2} \times \sum_{i=0}^{H} \sum_{k=0}^{h_{i}-1} k
$$

- $\quad$ The inventory balance equation (2) can be reformulated as:

$$
\hat{S}_{i, k+1}=\hat{S}_{i, k}+u_{i, k}-\hat{d}_{i, k} \quad k=0,1, \ldots ., h_{i}-1 ; i=1, \ldots . ., H
$$

Proof:

The inventory variable $S_{k}$ is statistically described by its mean $E\left\{S_{i, k}\right\}=\hat{S}_{i, k}$ and variance

$$
E\left\{\left(S_{i, k}-\hat{S}_{i, k}\right)^{2}\right\}=\operatorname{Var}\left(S_{i, k}\right) .
$$

The expected inventory cost is:

$$
C_{s} \cdot E\left\{S_{i, k}^{2}\right\}=C_{s} \cdot \hat{S}_{i, k}^{2}
$$

The balance equation (2) can be converted into an equivalent inventory balance equation, as follows

$$
\begin{gathered}
(2) \Rightarrow E\left\{S_{i, k+1}\right\}=E\left\{S_{i, k}\right\}+u_{i, k}-E\left\{d_{i, k}\right\} \\
\Rightarrow \hat{S}_{i, k+1}=\hat{S}_{i, k}+u_{i, k}-\hat{d}_{i, k}
\end{gathered}
$$

Equation (9) represents the mean variation of inventory at each period $k, k \in\{1,2, \ldots . ., N-1\}$ . Furthermore, $u_{i, k}$ is deterministic, since it does not depend on the random variables $d_{k}$ and $S_{k}$. That is, $E\left\{u_{i}\right\}=u_{i, k}$ with $V\left(u_{i, k}\right)=0 \quad \forall k$. Taking the difference between (2) and (9):

$$
\begin{gathered}
S_{i, k+1}-\hat{S}_{i, k+1}=S_{i, k}-\hat{S}_{i, k}-\left(d_{i, k}-\hat{d}_{i, k}\right) \\
\Rightarrow\left(S_{i, k+1}-\hat{S}_{i, k+1}\right)^{2}=\left(\left(S_{i, k}-\hat{S}_{i, k}\right)-\left(d_{i, k}-\hat{d}_{i, k}\right)\right)^{2} \\
\Rightarrow E\left(\left(S_{i, k+1}-\hat{S}_{i, k+1}\right)^{2}\right)=E\left(\left(\left(S_{i, k}-\hat{S}_{i, k}\right)-\left(d_{i, k}-\hat{d}_{i, k}\right)^{2}\right)\right.
\end{gathered}
$$




$$
\begin{gathered}
\Rightarrow E\left(\left(S_{i, k+1}-\hat{S}_{i, k+1}\right)^{2}\right)=E\left(\left(S_{i, k}-\hat{S}_{i, k}\right)^{2}+\left(d_{i, k}-\hat{d}_{i, k}\right)^{2}-2 \cdot\left(S_{i, k}-\hat{S}_{i, k}\right) \cdot\left(d_{i, k}-\hat{d}_{i, k}\right)\right) \\
\Rightarrow E\left(\left(S_{i, k+1}-\hat{S}_{i, k+1}\right)^{2}\right)=E\left(\left(S_{i, k}-\hat{S}_{i, k}\right)^{2}\right)+E\left(\left(d_{i, k}-\hat{d}_{i, k}\right)^{2}\right)-2 \cdot E\left(\left(S_{i, k}-\hat{S}_{i, k}\right) \cdot\left(d_{i, k}-\hat{d}_{i, k}\right)\right)
\end{gathered}
$$

Since $S_{k}$ and $d_{k}$ are independent random variables we can deduce that:

$$
E\left(\left(S_{i, k}-\hat{S}_{i, k}\right) \cdot\left(d_{i, k}-\hat{d}_{i, k}\right)\right)=E\left(\left(S_{i, k}-\hat{S}_{i, k}\right)\right) \cdot E\left(\left(d_{i, k}-\hat{d}_{i, k}\right)\right)
$$

Also, it is easy to see that:

$$
\begin{aligned}
& E\left(\left(S_{i, k}-\hat{S}_{i, k}\right)\right)=E\left(S_{i, k}\right)-E\left(\hat{S}_{i, k}\right)=0 \\
& E\left(\left(d_{i, k}-\hat{d}_{i, k}\right)\right)=E\left(d_{i, k}\right)-E\left(\hat{d}_{i, k}\right)=0
\end{aligned}
$$

Consequently,

$$
\begin{gathered}
E\left(\left(S_{i, k+1}-\hat{S}_{i, k+1}\right)^{2}\right)=E\left(\left(S_{i, k}-\hat{S}_{i, k}\right)^{2}\right)+E\left(\left(d_{i, k}-\hat{d}_{i, k}\right)^{2}\right) \\
\Rightarrow\left(\sigma_{s_{i, k+1}}\right)^{2}=\left(\sigma_{s_{i, k}}\right)^{2}+\left(\sigma_{d_{i, k}}\right)^{2}
\end{gathered}
$$

If we assume that $\sigma_{s}(0)=0$ and $\sigma_{d k}$ is constant and equal to $\sigma_{d}$ for all $k$ 's, we can deduce that:

$$
\begin{gathered}
\left(\sigma_{s_{i, k}}\right)^{2}=k \cdot\left(\sigma_{d_{i}}\right)^{2} \\
\Rightarrow E\left({S_{i, k}}^{2}\right)-\hat{S}_{i, k}{ }^{2}=k \cdot\left(\sigma_{d_{i}}\right)^{2} \\
\Rightarrow E\left({S_{i, k}}^{2}\right)=k \cdot\left(\sigma_{d_{i}}\right)^{2}+\hat{S}_{i, k}{ }^{2}
\end{gathered}
$$

Substituting (10) in the expected cost:

$$
F(u)=\sum_{i=0}^{H} C_{s} \cdot\left(h_{i} \cdot\left(\sigma_{d_{i}}\right)^{2}+\hat{S}_{i, h_{i}}{ }^{2}\right)+\sum_{i=0}^{H} \sum_{k=0}^{h_{i}-1}\left[C_{s} \cdot\left(k \cdot\left(\sigma_{d_{i}}\right)^{2}+\hat{S}_{i, k}{ }^{2}\right)+C_{p r} \cdot u_{i, k}{ }^{2}\right]
$$




$$
\begin{array}{r}
F(u)=\sum_{i=0}^{H} C_{s} \cdot\left(\hat{S}_{i, h_{i}}{ }^{2}\right)+\sum_{i=0}^{H} C_{s} \cdot\left(h_{i} \cdot\left(\sigma_{d_{i}}\right)^{2}\right)+\sum_{i=0}^{H} \sum_{k=0}^{h_{i}-1}\left[C_{s} \cdot\left(\hat{S}_{i, k}{ }^{2}\right)+C_{p r} \cdot u_{i, k}^{2}\right]+\sum_{i=0}^{H} \sum_{k=0}^{h_{i}-1}\left[C_{s} \cdot\left(k \cdot\left(\sigma_{d_{i}}\right)^{2}\right)\right] \\
F(u)=\sum_{i=0}^{H} C_{s} \cdot\left(\hat{S}_{i, h_{i}}{ }^{2}\right)+\sum_{i=0}^{H} \sum_{k=0}^{h_{i}-1}\left[C_{s} \cdot\left(\hat{S}_{i, k}{ }^{2}\right)+C_{p r} \cdot u_{i, k}^{2}\right]+\sum_{i=0}^{H} C_{s} \cdot\left(h_{i} \cdot\left(\sigma_{d_{i}}\right)^{2}\right)+\sum_{k=0}^{h_{i}-1}\left[C_{s} \cdot\left(k \cdot\left(\sigma_{d_{i}}\right)^{2}\right)\right] \\
F(u)=\sum_{i=0}^{H} C_{s} \cdot\left(\hat{S}_{i, h_{i}}{ }^{2}\right)+\sum_{i=0}^{H} \sum_{k=0}^{h_{i}-1}\left[C_{s} \cdot\left(\hat{S}_{i, k}{ }^{2}\right)+C_{p r} \cdot u_{i, k}^{2}\right]+\sum_{i=0}^{H} \sum_{k=0}^{h_{i}}\left[C_{s} \cdot\left(k \cdot\left(\sigma_{d_{i}}\right)^{2}\right)\right]
\end{array}
$$

$\sigma_{d \mathrm{i}}$ is constant and equal to $\sigma_{d}$

$$
F(u)=\sum_{i=0}^{H} C_{s} \cdot\left(\hat{S}_{i, h_{i}}{ }^{2}\right)+\sum_{i=0}^{H} \sum_{k=0}^{h_{i}-1}\left[C_{s} \cdot\left(\hat{S}_{i, k}^{2}\right)+C_{p r} \cdot u_{i, k}^{2}\right]+C_{s} \cdot\left(\sigma_{d}\right)^{2} \cdot \sum_{i=0}^{H} \sum_{k=0}^{h_{i}} k
$$

- $\quad$ Service level constraint:

It is worth noting that the demand is a random variable that must be estimated. So, the inventory-production dynamic system is contaminated by the randomness and it becomes a stochastic process. However, only the inventory variable is affected and, so that is the reason why it is a stochastic variable while the production rate is deterministic variable.

Using the above notations, the first constraint describing the stock levels can be written under a deterministic form as follows:

$$
\hat{S}_{i, k+1}=\hat{S}_{i, k}+u_{i, k}-\hat{d}_{i, k} \quad k=0,1, \ldots ., h_{i}-1 ; i=1, \ldots . ., H
$$

The service level constraint is transformed into equivalent constraint, but deterministic, inequalities by specifying through the following lemma a certain minimum cumulative production quantities that depend on the service level requirements.

Furthermore, the equation describing the service rate can be transformed as follows [8]:

\section{Lemma 2}

For $k \in\left\{0,1, \ldots, h_{i}-1\right\} ; i \in\{0,1, \ldots, H\}$ we have:

$$
\operatorname{Pr} o b\left(S_{i, k+1} \geq 0\right) \geq \alpha \Rightarrow\left(u_{i, k} \geq V_{d, i, k} \cdot \varphi_{d, k, i}^{-1}(\alpha)+\hat{d}_{i, k}-\hat{S}_{i, k}\right)
$$


$\varphi_{d, k, i}$ : Cumulative Gaussian distribution function with mean $\hat{d}_{i, k}$ and finite variance $\operatorname{Var}\left(d_{i, k}\right)=V_{d, i, k} \geq 0$

$V_{d, k}:$ Variance of demand $d$ at period $k$

Proof:

$$
\begin{gathered}
S_{i, k+1}=S_{i, k}+u_{i, k}-d_{i, k} \\
\Rightarrow \operatorname{Pr} o b\left(S_{i, k+1} \geq 0\right) \geq \alpha \\
\Rightarrow \operatorname{Pr} o b\left(S_{i, k}+u_{i, k}-d_{i, k} \geq 0\right) \geq \alpha \\
\Rightarrow \operatorname{Pr} o b\left(S_{i, k}+u_{i, k} \geq d_{i, k}\right) \geq \alpha \\
\Rightarrow \operatorname{Pr} o b\left(S_{i, k}+u_{i, k}-\hat{d}_{i, k} \geq d_{i, k}-\hat{d}_{i, k}\right) \geq \alpha \\
\Rightarrow \operatorname{Pr} o b\left(\frac{S_{i, k}+u_{i, k}-\hat{d}_{i, k}}{V_{d, i, k}} \geq \frac{d_{i, k}-\hat{d}_{i, k}}{V_{d, i, k}}\right) \geq \alpha
\end{gathered}
$$

Note that $\left(\frac{d_{i, k}-\hat{d}_{i, k}}{V_{d, i, k}}\right)$ is a Gaussian random variable with an identical distribution as $d_{k}$.

It is possible from (12) to determine a lower bound for the control variable. Hence,

$$
\varphi_{d, k}\left(\frac{S_{i, k}+u_{i, k}-\hat{d}_{i, k}}{V_{d, i, k}}\right) \geq \alpha
$$

We note that $\varphi_{d, k}$ is indefinitely differentiable, so we conclude that $\varphi_{d, k}$ is invertible.

$$
\text { Thus (13) } \Rightarrow \frac{S_{i, k}+u_{i, k}-\hat{d}_{i, k}}{V_{d, i, k}} \geq \varphi_{d, k}^{-1}(\alpha)
$$




$$
\begin{gathered}
\Leftrightarrow u_{i, k} \geq V_{d, i, k} \cdot \varphi_{d, k}^{-1}(\alpha)+\hat{d}_{i, k}-S_{i, k} \\
k \in\left\{0,1, \ldots, h_{i}-1\right\} ; i \in\{0,1, \ldots, H\}
\end{gathered}
$$

Thus

$$
\begin{gathered}
\operatorname{Pr} o b\left(S_{i, k+1} \geq 0\right) \geq \alpha \Rightarrow\left(u_{i, k} \geq V_{d, i, k} \cdot \varphi_{d, k, i}^{-1}(\alpha)+\hat{d}_{i, k}-S_{i, k}\right) \\
k \in\left\{0,1, \ldots, h_{i}-1\right\} ; i \in\{0,1, \ldots, H\}
\end{gathered}
$$

\subsection{MAINTENANCE COST}

For the maintenance policy, we seek to determine the optimal maintenance strategy characterized by the optimal number $N^{*}$ of preventive maintenance actions and the time between them $T^{*}$, as given by Eq. (14).

$$
T^{*}=\frac{L}{N^{*}}
$$

The analytic expression of the total maintenance cost is as follows, with $N \in\{1,2,3 \ldots .$.

$$
C_{M}(U, N)=(N-1) \cdot M_{p}+M_{c} \cdot A(U, N)
$$

Recall that $A(U, N)$ corresponds to the average number of failures that occur during the horizon $(L-X) . \Delta t$, considering the production rate in each production period $\Delta t$.

\section{- MACHINES DegRadation}

Inspired especially by the work [8], in our present work, we take into account the degradation of workstations while forecasting the maintenance actions. Thus, the maintenance strategy depends strongly on production planning which is on accordance with the principle of joint production and maintenance planning.

Dealing with this section, we assume that preventive actions should be scheduled at the end of a production period.

Furthermore, we assume that the equipment degradation is linear. So, we were inspired from the work [8] where the author dealt with only one machine over a finite time horizon therefore, he expressed the failure rate function during a period $k$ as follows:

$$
\lambda_{k}(t)=\lambda_{k-1}(\Delta t)+\Delta \lambda_{k}(t) \cdot \lambda_{n}(t) \quad \forall t \in[0, \Delta t]
$$


Zied Hajej, Nidhal Rezg, and Ali Gharbi

$$
\text { With } \lambda_{k=0}=\lambda_{X} \text { and } \Delta \lambda_{k}(t)=\frac{u_{k} / \Delta t}{U^{m a x} / \Delta t} \cdot \lambda_{n}(t)
$$

$\lambda_{n}(t)$ : failure rate for nominal conditions which is equivalent to the failure rate with maximal production rate.

The average number of failure over the horizon $(L-X) . \Delta t$ is:

$$
\begin{aligned}
& A(U, N)=\sum_{j=0}^{N-1}\left[\sum_{i=\operatorname{In}\left(j \cdot \frac{T}{\Delta t}\right)+\frac{X}{\Delta t}+1}^{\operatorname{In}\left((j+1) \cdot \frac{T}{\Delta t}\right)+\frac{X}{\Delta t}} \int_{0}^{\Delta t} \lambda_{i}(t) d t\right] \\
& +\sum_{j=0}^{N-1}\left[\left(\int_{0}^{\left((j+1) \times T-\operatorname{In}\left((j+1) \times \frac{T}{\Delta t}\right) \times \Delta t\right)} \lambda_{I n}\left((j+1) \times \frac{T}{\Delta t}\right)+\frac{X}{\Delta t}+1\right.\right. \text { (t) } \\
& +\sum_{j=0}^{N-1}\left[\int_{(j+1) \times T+\frac{X}{\Delta t}}^{\left(\operatorname{In}\left((j+1) \times \frac{T}{\Delta t}\right)+1+\frac{X}{\Delta t}\right) \times \Delta t} \frac{\left(u_{\left(\operatorname{In}\left((j+1) \times \frac{T}{\Delta t}\right)+1+\frac{X}{\Delta t}\right) / \Delta t}\right)}{U^{\max } / \Delta t} \times \lambda_{n}(t) d t\right]
\end{aligned}
$$

With:

$$
T=\frac{(L-X)}{N} \cdot \Delta t ; X=\delta \cdot \Delta t \quad \delta \in \mathbb{N}^{*}
$$

In denote the integer part 


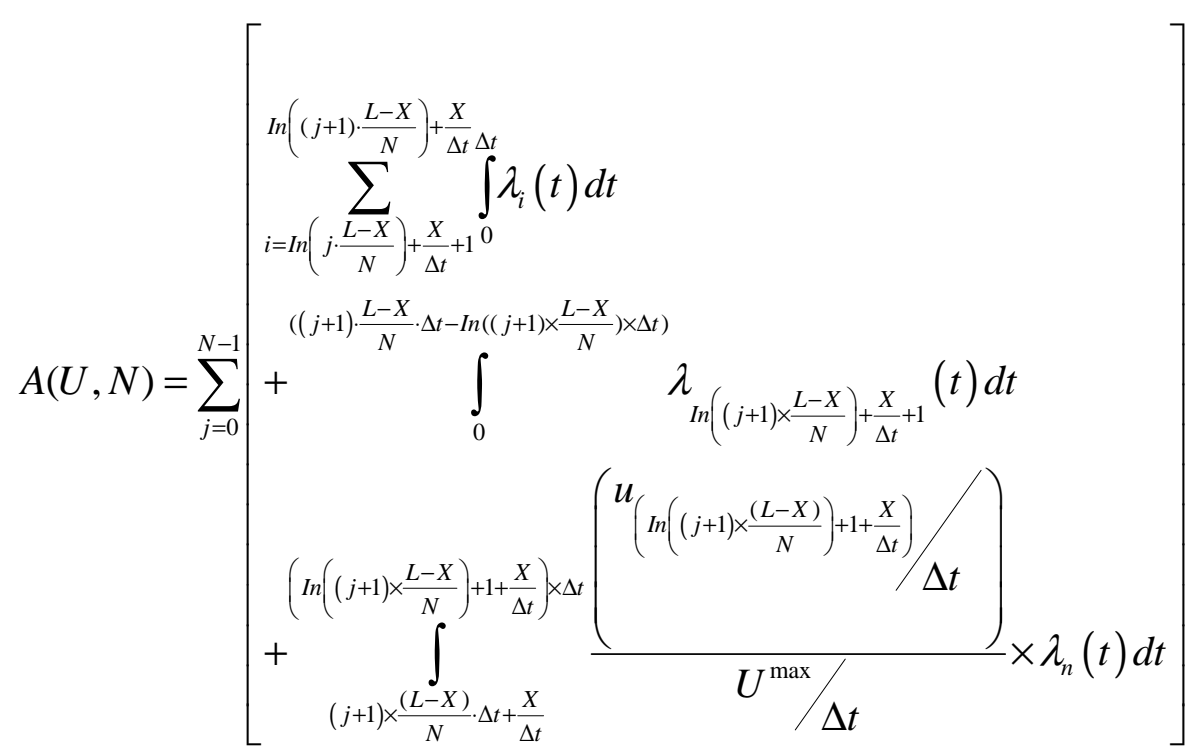

\section{NUMERICAL EXAMPLE (RESULTS)}

\subsection{INPUT DATA}

We consider the following arbitrarily chosen input data and that in order to illustrate our approach and mainly to prove the validity of our model and that we can find feasible solutions.

Concerning the production period time $\Delta \mathrm{t}$ and the finite horizon time:

$H=2 ; \Delta t=1 ; h_{1}=15 ; h_{2}=15 ; \quad L . \Delta t=\sum_{i=1}^{H} h_{i} \cdot \Delta t=30$ months

The lower and upper boundaries of production capacities: $U^{\min }=0$ and $U^{\max }=17$.

The production and inventory unity costs: $C_{p r}=3 \mathrm{mu}, C s=6 \mathrm{mu} / \mathrm{k}, S_{0}=20$

Since we assume that the demand is random and assumed Gaussian with standard deviation $\sigma_{d}=1.2$

The customer satisfaction degree, associated with the stock constraint, is equal to $90 \%$ $(\alpha=0.9)$.

Point of view reliability, we suppose that the failure time of machine $M$ has a degradation law characterized by a Weibull distribution. The Weibull scale and shape parameters are respectively $\beta=100$ and $\gamma=2$.

To compute the failure rate, we assume that the nominal degradation follows a Weibull distribution given by: 
Zied Hajej, Nidhal Rezg, and Ali Gharbi

$$
\lambda_{n}(t)=\frac{\gamma}{\beta} \cdot\left(\frac{t}{\beta}\right)^{\gamma-1}
$$

The average demand of $h_{1}$ and $h_{2}$ is presented in tables I and II below:

\begin{tabular}{|c|c|c|c|c|}
\hline$d_{1}$ & $d_{2}$ & $d_{3}$ & $d_{4}$ & $d_{5}$ \\
\hline $\mathbf{1 5}$ & $\mathbf{1 7}$ & $\mathbf{1 5}$ & $\mathbf{1 5}$ & $\mathbf{1 5}$ \\
\hline$d_{6}$ & $d_{7}$ & $d_{8}$ & $d_{9}$ & $d_{10}$ \\
\hline $\mathbf{1 4}$ & $\mathbf{1 6}$ & $\mathbf{1 4}$ & $\mathbf{1 6}$ & $\mathbf{1 3}$ \\
\hline$d_{11}$ & $d_{12}$ & $d_{13}$ & $d_{14}$ & $d_{15}$ \\
\hline $\mathbf{1 5}$ & $\mathbf{1 4}$ & $\mathbf{1 5}$ & $\mathbf{1 2}$ & $\mathbf{1 5}$ \\
\hline
\end{tabular}

Table 1: Average Demand: $h_{1}$

\begin{tabular}{|c|c|c|c|c|}
\hline$d_{1}$ & $d_{2}$ & $d_{3}$ & $d_{4}$ & $d_{5}$ \\
\hline $\mathbf{1 3}$ & $\mathbf{1 5}$ & $\mathbf{1 1}$ & $\mathbf{1 6}$ & $\mathbf{1 3}$ \\
\hline$d_{6}$ & $d_{7}$ & $d_{8}$ & $d_{9}$ & $d_{10}$ \\
\hline $\mathbf{1 5}$ & $\mathbf{1 2}$ & $\mathbf{1 4}$ & $\mathbf{1 6}$ & $\mathbf{1 4}$ \\
\hline$d_{11}$ & $d_{12}$ & $d_{13}$ & $d_{14}$ & $d_{15}$ \\
\hline $\mathbf{1 5}$ & $\mathbf{1 3}$ & $\mathbf{1 5}$ & $\mathbf{1 2}$ & $\mathbf{1 6}$ \\
\hline
\end{tabular}

TABLE 2: Average Demand: $h_{2}$

\subsection{OPTIMALS PRODUCTION AND MAINTENANCE PLANS}

We used the Exact Global Optimization method with MATHEMATICA, in order to realize this optimization. The economically production plans of $h_{1}$ and $h_{2}$, the optimal choice of warranty periods $X^{*}$ and the optimal maintenance scheduling are presented respectively in table III, table IV and figure 3 . 
- Optimal production plans

\begin{tabular}{|c|c|c|c|c|}
\hline$u^{*}(1)$ & $u^{*}(2)$ & $u^{*}(3)$ & $u^{*}(4)$ & $u^{*}(5)$ \\
\hline $\mathbf{9}$ & $\mathbf{1 4}$ & $\mathbf{8}$ & $\mathbf{1 2}$ & $\mathbf{1 2}$ \\
\hline$u^{*}(6)$ & $u^{*}(7)$ & $u^{*}(8)$ & $u^{*}(9)$ & $u^{*}(10)$ \\
\hline $\mathbf{1 5}$ & $\mathbf{9}$ & $\mathbf{1 3}$ & $\mathbf{1 4}$ & $\mathbf{1 1}$ \\
\hline$u^{*}(11)$ & $u^{*}(12)$ & $u^{*}(13)$ & $u^{*}(14)$ & $u^{*}(15)$ \\
\hline $\mathbf{1 0}$ & $\mathbf{5}$ & $\mathbf{1 1}$ & $\mathbf{1 2}$ & $\mathbf{5}$ \\
\hline
\end{tabular}

TABLE 3. Optimal Production Plan: $h_{1}$

\begin{tabular}{|c|c|c|c|c|}
\hline$u^{*}(1)$ & $u^{*}(2)$ & $u^{*}(3)$ & $u^{*}(4)$ & $u^{*}(5)$ \\
\hline $\mathbf{1 5}$ & $\mathbf{1 6}$ & $\mathbf{1 2}$ & $\mathbf{1 0}$ & $\mathbf{6}$ \\
\hline$u^{*}(6)$ & $u^{*}(7)$ & $u^{*}(8)$ & $u^{*}(9)$ & $u^{*}(10)$ \\
\hline $\mathbf{2}$ & $\mathbf{5}$ & $\mathbf{1 7}$ & $\mathbf{3}$ & $\mathbf{1 4}$ \\
\hline$u^{*}(11)$ & $u^{*}(12)$ & $u^{*}(13)$ & $u^{*}(14)$ & $u^{*}(15)$ \\
\hline $\mathbf{9}$ & $\mathbf{1 0}$ & $\mathbf{3}$ & $\mathbf{1 6}$ & $\mathbf{7}$ \\
\hline
\end{tabular}

TABLE 4. Optimal Production Plan: $h_{2}$

- $\quad$ Optimal warranty periods $X^{*}$ and optimal number of preventive maintenance $N^{*}$

(i) Failure rate at the end of warranty periods $\lambda_{x} \in[0,1]$.

(ii) Costs associated with a corrective and preventive maintenance action after warranty periods are respectively

$M_{c}(X=7 \cdot \Delta t)=8500 \mathrm{mu} ; M_{p}(X=7 \cdot \Delta t)=1000 \mathrm{mu}$ (monetary unit) and

$M_{c}(X=(j+1) \cdot \Delta t)=\delta \cdot M_{c}(X=j \cdot \Delta t)(j=7,8, \ldots .$.

$M_{p}(X=(j+1) \cdot \Delta t)=\delta \cdot M_{p}(X=j \cdot \Delta t)(j=7,8, \ldots .$.

and $\delta=1.3$

We find the values of $X$ and $N$ which corresponds to the lowest total maintenance cost value by using the MATHEMATICA. Figure 3 shows the total maintenance cost in function of the warranty periods $X$ and number of preventive maintenance actions $N$. We can see that the lowest total cost value corresponds to $X^{*}=14$ and $N^{*}=2$. Therefore, over the finite horizon $H$ of 30 months, Two preventive maintenance actions should be done, i.e. for every period equals to $T^{*}=(L-X) / N_{*}=8 t u$ a preventive maintenance action should be done. 
For $\lambda_{(\mathrm{X}=7)}=\mathbf{0 . 2}$

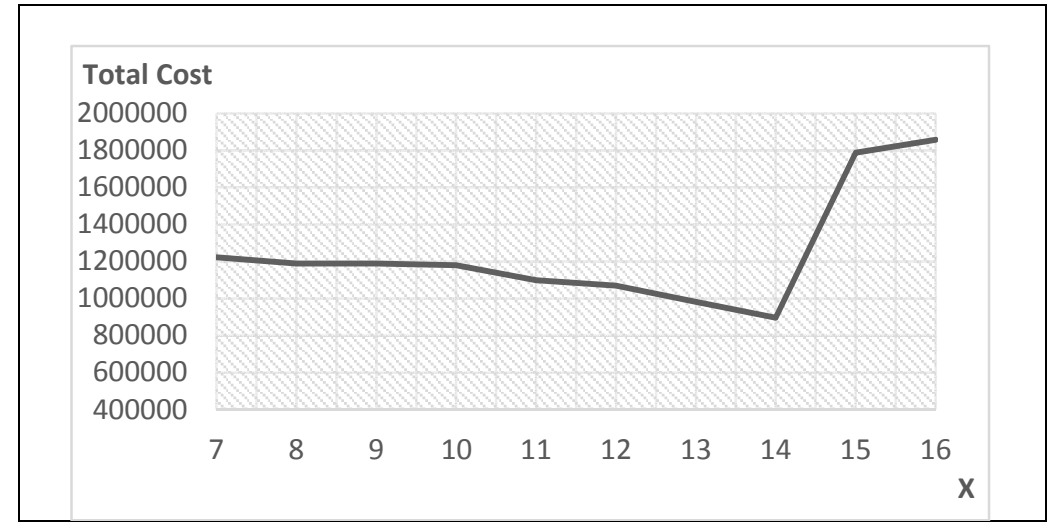

Figure 3: Total maintenance cost as function of warranty periods $\mathrm{X}$ $\mathrm{X}^{*}=14, \mathrm{~N}^{*}=2$

\subsection{SENSITIVITY STUDY}

For the corrective and preventive maintenance costs: $M c(X=1)=8500 \mathrm{mu} ; M p(X=1)=500 \mathrm{mu}$ $M c(X=(j+1) \cdot \Delta t)=\delta \cdot M c(X=j . \Delta t)(j=7,8, \ldots .$.$) ;$ $M p(X=(j+1) \cdot \Delta t)=\delta . M p(X=j . \Delta t)(j=7,8, \ldots$. and $\delta=1.1$

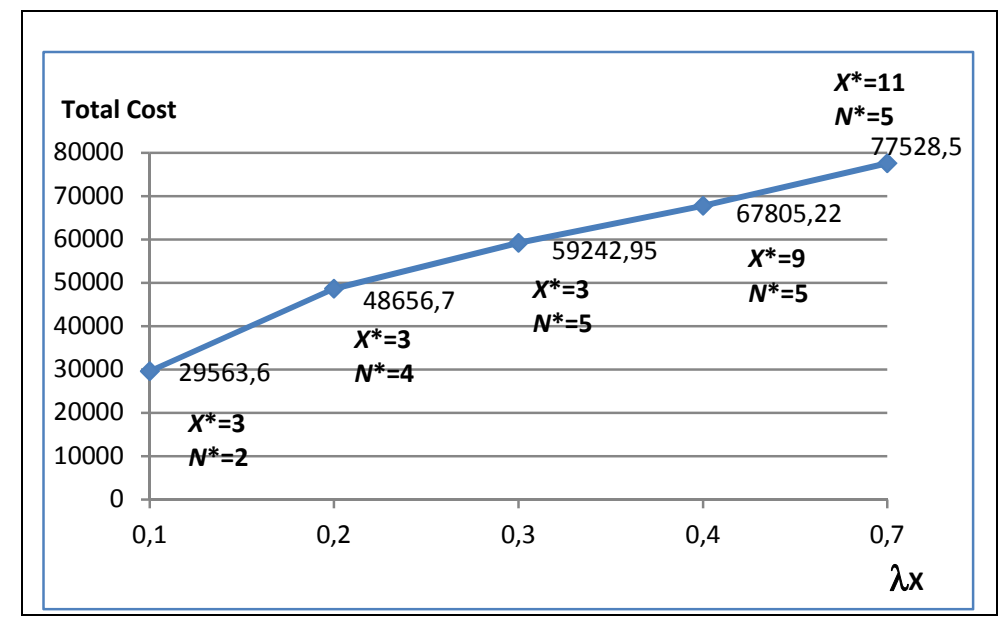

Figure 4: Total maintenance cost as function of failure rate $\lambda_{X}$ 
An Optimal Production/Maintenance Strategy under Lease Contract with Warranty Periods

Hence, from figure 4 , we can see that the higher value of failure rate $\lambda_{X}$ corresponds to the higher of the optimal total maintenance cost, the optimal of warranty periods and the optimal number of preventive maintenance actions. This can be explained by the fact that, as failure rate $\lambda_{X}$ increases, the average number of failure increase consequently the optimal number of preventive maintenance and in this case is preferably choose the highest optimal warranty periods. According to the previous results presented through the variability of $X$ and $\lambda_{\mathrm{X}}$, warranty periods is really impacted visibly.

\section{Conclusion}

We tried in the present work to study a relatively new approach consisting in optimizing jointly production and maintenance systems for leased equipment considering a warranty periods in the leasing contract. The contribution and novelty of this work is that it treats this approach under new constraints related especially to leasing techniques with warranty periods.

In order to reduce the failure rate, preventive maintenance actions are planned. Given the necessary service level, we have formulated and solved the related stochastic production/maintenance problem. A joint optimization has been performed obtaining an optimal production plan as well as the corresponding preventive maintenance periods. We take into account the influence; on one hand, of warranty periods and on the other hand, of failure rate value at the end of guarantee periods on the maintenance strategy. A numerical example and sensitivity study have been presented illustrating the proposed approach.

\section{REFERENCES}

[1] Nakagawa, T. A summary of periodic replacement with minimal repair at failure. Journal of the Operations Research Society of Japan, 1981, 24: 213-227.

[2] Pham, H., \& Wang, H. Imperfect maintenance. European Journal of Operational Research, 1996, 94: 425-438.

[3] Wang, H. A survey of maintenance policies of deteriorating systems. European Journal of Operational Research, 2002, 139: 469-489.

[4] C.C. Holt, F. Modigliani, J.F.Muth, and H.A.Simon, Planning Production, Inventory and Work Force. Prentice-Hall, NJ, 1960.

[5] Hu, J., Vakili, P. and Yu, G. Optimality of hedging point policies in the production control of failure prone manufacturing systems. Automatic Control, IEEE Transactions, 1994, 39 (9): 1875-1880.

[6] Hajej, Z., S. Dellagi and N. Rezg. An optimal production/maintenance planning under stochastic random demand, service level and failure rate. IEEE International Conference on Automation Science and Engineering, Bangalore, Aout 21-23, 2009, pp. 292 -297.

[7] Hajej Z., Dellagi S., Rezg N. Optimal integrated maintenance/production policy for randomly failing systems with variable failure rate. International Journal of Production Research, 2011, 49(19):5695-5712.

[8] Desai, P., and Purohit, D. Leasing and Selling: Optimal Marketing Strategies for a Durable Goods Firm, Management Science, 1998, 44:19-34. 
Zied Hajej, Nidhal Rezg, and Ali Gharbi

[9] kenne, J. P. and Gharbi, A. Control of production and corrective maintenance rates in a multiple-product manufacturing system. Mathematical And Computer Modelling, 2004, 38:865-875.

[10] Ouali, Me, S., Rezg, N., and Xie, X. Maintenance préventive et optimisation des flux d'un syctème de production. Journal Européen des Systèmes Automatisés (JESA),2002 , 36:97116.

[11] Rezg, N., Mati, Y., and Xie, X. Joint optimization of preventive maintenance and inventory control in a production line using simulation. International journal of Production Research, 2004, 44:2029-2046.

[12] CHELBI, A. and Ait-KADI, D. Analysis of a production/inventory system with random failing production unit submitted to regular preventive maintenance. European journal of operational research, 2004, 156:712-718.

[13] WASSY SORO, I., AÏT-KADI, D. and NOURELFATH, M. Production Rate Maximization of a Multi-State System under Inspection and Repair Policy. International Journal of Performability Engineering, 2012, 8: 4, pp. $409-416$.

[14] CHARI, N., DIALlO, C., and VENKATADRI, U. Optimal Unlimited Free-Replacement Warranty Strategy using Reconditioned Products. International Journal of Performability Engineering. 2013, 9: 2, - Paper 6 - pp. 191-200.

[15] HAJEJ, Z., REZG, N., and GHARBI, A. A decision optimization model for leased manufacturing equipment with warranty under forecasting production/maintenance problem. Mathematical Problems in Engineering. Volume 2015 (2015), Article ID 274530, http://dx.doi.org/10.1155/2015/274530 